\title{
"HIEROGLIFICOS Y EMPRESAS" EN LA CUSTODIA HISPALENSE DE JUAN DE ARFE*
}

\author{
"HIEROGLYPHICS AND ENTERPRISES" IN THE \\ SEVILLIAN MONSTRANCE OF JUAN DE ARFE
}

\author{
PATRICIA ANDRÉS GONZÁLEZ** \\ Universidad de Valladolid, España \\ patricia@fyl.uva.es
}

\begin{abstract}
Tras la custodia de la catedral de Ávila (1564-1571), Juan de Arfe realiza su obra más importante la de Sevilla (1580-1587). En ella introduce una serie de "hieroglificos" que él mismo explica, al dictado del creador del programa iconográfico, el canónigo de la catedral Francisco Pacheco, en Descripción de la traza y ornato de la custodia de plata de la Sancta Iglesia de Sevilla. Sin embargo, el estudio pormenorizado de la obra realizada arroja algunas diferencias respecto al texto. En este estudio se analizan esas divergencias, y las fuentes en las que se basa, junto a su significado dentro del conjunto. Además, se comparan con las empresas que realiza para su otra custodia importante, la de Valladolid (1587-1590).

Palabras clave: Juan de Arfe; Platería; Custodia; Sevilla; Emblemática.
\end{abstract}

Juan de Arfe performs his most important work, the monstrance of the Cathedral of Seville, between 1580-1587, following finish the monstrance of Avila (1564-1571). In it introduces "hieroglyphics", that he explains in Descripción de la traza y ornato de la custodia de plata de la Sancta Iglesia de Sevilla, under the directions of the iconographic program, Francisco Pacheco. However, the detailed study shows some differences. In this study we analyze these differences, the sources and the meaning of the hieroglyphics. Also we compare it with his other important monstrance, Valladolid (1587-1590).

Keywords: Juan de Arfe; silverware; monstrance; Seville; emblematic.

El avance en los estudios de la literatura emblemática nos está permitiendo entender el significado de un gran número de obras de arte, entre ellas, las piezas de orfebrería y platería, hasta hace poco tiempo relegadas prácticamente del

* Quiero agradecer al Cabildo Catedral de Sevilla y en concreto a la prof. ${ }^{\text {a }}$ Teresa Laguna Paúl que me permitiesen acceder al estudio directo de la obra.

** GIR "Patrimonio e iconografía en la Corona de Castilla". 
análisis de la imagen ${ }^{1}$. Sin embargo, algunas de estas piezas tienen unos programas iconográficos de gran interés, y en muchas ocasiones complejos y de gran profundidad intelectual, gracias a la presencia de las formas emblemáticas. Es el caso de dos de las custodias que realiza Juan de Arfe, las de Sevilla y Valladolid.

En esta ocasión nos interesa analizar la primera de ellas, la hispalense (figura 1), que la historiografía artística ha considerado fuente de inspiración para elaborar las empresas la custodia pinciana. La sevillana contiene dieciocho formas emblemáticas, seis en cada uno de los tres cuerpos inferiores, siguiendo el programa iconográfico que diseña el canónigo de la catedral, Francisco Pacheco. Es considerada sin duda como su mejor obra, bien conocida a través del magnífico estudio de la profesora Sanz Serrano ${ }^{2}$. En él mismo se describen las empresas, dentro del conjunto del programa iconográfico. Ahora queremos profundizar en su análisis, buscando las fuentes y el significado específico de las mismas, y poniéndolas en relación con otras obras de Arfe.

Para su descripción y análisis vamos a seguir el folleto, Descripción de la traza y ornato de la custodia de plata de la Sancta Iglesia de Sevilla, que publica el propio Arfe en 1587, en casa de Andrea Percioni y Juan de León. Prácticamente han desaparecido todos los ejemplares del mismo ${ }^{3}$, y conocemos el texto a través de varios resúmenes y una edición reciente ${ }^{4}$. En él recoge el programa iconográfico de la custodia y hace, lógicamente, referencia a los jeroglíficos.

\section{DESCRIPCIÓN DE LAS EMPRESAS Y JEROGLÍFICOS}

El texto de Arfe recoge que en el primer cuerpo "en los medios de los seis lados del freso lleva los hieroglíficos y empresas siguientes en unos óvalos, y la letra de

${ }^{1}$ ANDRÉS GONZÁLEZ, Patricia: "Emblemática y orfebrería en Castilla y León: la custodia de Juan de Arfe en la catedral de Valladolid", en Paisajes emblemáticos: la construcción de la imagen simbólica en Europa y América, Badajoz, 2008, pp. 517-534. ANDRÉS GONZÁLEZ, Patricia: Arte, fiesta e iconografía en torno a la Eucaristía: la custodia procesional de Valladolid, Valladolid, 2011.

${ }^{2}$ SANZ SERRANO, M. ${ }^{a}$ Jesús: Juan de Arfe y Villafañe y la custodia de Sevilla, Sevilla, 1978.

${ }^{3}$ LÓPEZ PLASENCIA, José Cesareo: "Un ejemplar inédito de la 'Descripción de la traça y ornato de la Custodia de Plata de la Sancta Iglesia de Sevilla', del 'escultor de oro y plata' Juan de Arfe y Villafañe, en la Universidad de La Laguna”, en RIVAS CARMONA, Jesús, (coord.), Estudios de platería: San Eloy 2008, Servicio de Publicaciones de la Universidad de Murcia, 2008, pp- 315-337.

${ }^{4}$ En 1865 se publica un resumen de Juan Agustín Ceán Bermúdez, sobre otro aparecido en 1805 en el Viage por España, de Ponz. La primera reedición completa es en la revista Archivo Hispalense en 1885, con los comentarios de Ceán y sus dibujos. Hace unos años, en 2010 Juan José Antequera Luengo ha publicado una nueva edición, en el Foro Andaluz de Cooperación. 
ellos en la cinta mayor del architrave". Efectivamente las formas emblemáticas de este primer cuerpo, se colocan en el medio de cada tramo curvo y sobresaliente de la planta, el arquitrabe.

El primer jeroglífico es "Una guirnalda de pámpanos y espigas, y en medio una granada abierta, que significa la Iglesia por la multitud y unión de sus granos, guarnecida con la fortaleza de este Sanctisimo Sacramento, con esta letra: Posuit fines tuos pacem". El lema está tomado del Salmo 147, en concreto el versículo 3.

Sanz Serrano, siguiendo el texto de la Descripción, dice que la granada abierta "significa la Iglesia por la multitud y unión de sus granos, protegida por racimos y espigas, símbolo del Sacramento" ". La granada ha sido símbolo de unión, si bien en la Antigüedad no estaba claro su significado ${ }^{6}$. Pero aquí no se trata simplemente de una alusión a ese significado general, sino que remite a su uso por parte de los Padres de la Iglesia quienes lo relacionan con la imagen de la Iglesia: bajo una misma creencia se reúnen diferentes pueblos. Ya Piero Valeriano lo recoge diciendo "De malo púnico. Multarum Gentium societas".

También en las empresas de Remón ${ }^{7}$ se recoge ese simbolismo de la multiplicidad y unidad a través de la granada, ayudada o protegida por Dios o por María. En ella aparece un árbol del Granado, lleno de sus frutos. Pero lo interesante es el comentario, en el que indica "por la granada, que porque abraça dentro de una corteza, tantos granos, y allí los ha de madurar y conservar desde que nace en la rama sale coronada, singular hermosura entre las demás frutas..."

En el jeroglífico realizado en la custodia hispalense se reconoce la granada, abierta, que según la Descripción de Arfe debía estar protegida por símbolos claros de la eucaristía, el pámpano y la espiga, la uva y el pan, la sangre y la carne de Cristo. Estos elementos no están representados de una forma muy clara, pero sin duda hay una guirnalda de frutos. Como indica el texto de la Descripción, la Iglesia en su multitud será fortalecida gracias a la práctica eucarística.

A continuación, el segundo jeroglífico habla de "Una mano que entre las nubes se extiende sobre un nido de pollos de cuervo, los cuales tienen los picos abiertos y levantados, y la letra: Quanto magis vos. Significando que el mesmo Señor que tiene cuidado de sustentar los paganos o infieles, tiene particular providencia en sustentar su Iglesia con la hartura deste manjar celestial" (figura 2).

El lema es de los evangelistas. Mateo lo utiliza $(6,30)$, pero también aparece en Lucas, quien realmente sirve de fuente: "Considerad los cuervos, que ni siembran,

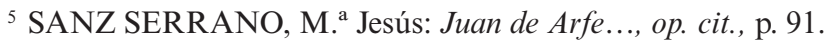

${ }^{6}$ Recoge una cita de Pausanias (II, cap. 17). "De la granada no diré nada, porque su historia pertenece a los misterios sagrados". TERVARENT, Guy de: Atributos y símbolos en el arte profano. Diccionario de un lenguaje perdido, Barcelona, 2002, p. 277.

${ }^{7}$ REMÓN, Alonso: Discursos elógicos y apologéticos. Empresas y divisas sobre las triunfantes vida y muerte del glorioso patriarca San Pedro de Nolasco..., Madrid, 1627, fol. 28r. 
ni siegan; que ni tienen despensa, ni granero, y Dios los alimenta. ¡Cuánto más valéis vosotros que las aves!" (12, 24).

La mano ha sido símbolo fundamentalmente de Dios, así lo señala Sanz Serrano quien indica varios significados concretos del jeroglífico ${ }^{8}$ : es Dios protegiendo y alimentando a sus hijos, pero también es símbolo de la Eucaristía, y sobre todo de la parábola en la que Dios Padre cuida hasta de los lirios del campo, al que se refiere el pasaje de Mateo y de Lucas.

El cuervo ha sido utilizado con un simbolismo negativo ${ }^{9}$, pero en este caso nos encontramos con un nido de polluelos, basada en la supuesta propiedad que recogen los Bestiarios, en los que las crías al nacer son blancas, por lo que sus padres no los reconocen y les niegan el alimento. En la Biblia, dos citas remiten a ello: Job, 38, 41 (“¿Quién prepara su provisión al cuervo, cuando sus crías gritan hacia Dios, cuando se estiran faltos de comida?") y el Salmo 147 ("Cantad a Yahveh en acción de gracias... el que dispensa al ganado su sustento y a las crías de los cuervos cuando chillan"). Entre las interpretaciones dadas a este texto, a parte de San Gregorio Magno que lo relaciona con los doctores de la Iglesia, nos interesa Rábano Mauro, que siguiendo a San Isidoro de Sevilla, reconoce a los polluelos como el pueblo de los gentiles que quieren convertirse al cristianismo.

En la Hieroglyphica de Pierio Valeriano este comportamiento es considerado como símbolo de la benignidad de Dios, que es lo que simbolizaría aquí. Y otros emblemas, como algunos de los recogidos por Filippo Picinelli en el siglo XVIII, aluden a esa ayuda de Dios. También en otra serie conocida de emblemas eucarísticos, como la del francés Augustin Chesneau ${ }^{10}$, en concreto en el número 37, el ave que alimenta a los polluelos es Cristo que, con su cuerpo y sangre, hace lo mismo con sus discípulos.

El tercero de los jeroglíficos de este primer cuerpo es "Una hermosa caña de trigo, de la cual salen siete espigas muy gruesas y la letra: Sempiterna facietas. Demostrando que no como en los siete años de Egipto, sino que perpetuamente ha de durar en la Iglesia de Cristo la abundancia y hartura espiritual, por esta sagrada mesa de su cuerpo y sangre".

En principio el significado del mismo puede parecer obvio, al aparecer el trigo y espigas en un contexto eucarístico. Sin embargo, la elaboración es más compleja pues esa caña con sus siete espigas tiene como fuente el Génesis y el pasaje del sueño del faraón (capítulo 41) en el que se predice los siete años de abundancia y los siete de penuria en Egipto ${ }^{11}$. Faltaría en el cuerpo del jeroglífico la alusión de los años de escasez, porque lo que precisamente se quiere mostrar a través

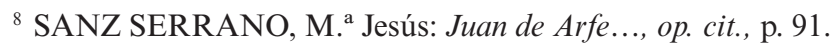

${ }^{9}$ GARCÍA ARRANZ, José Julio: Ornitología emblemática. Las aves en la literatura simbólica ilustrada en Europa durante los siglos XVI y XVII, Cáceres, 1996, 1º edición, p. 328.

${ }^{10}$ CHESNAU, Augustin: Orpheus eucharisticus, París, 1657.

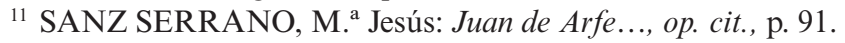


de la imagen y con el mote, es que el alimento sagrado de la eucaristía es eterno. El aspecto, la facies, con la práctica de la eucaristía será siempre de abundancia.

El cuarto dice "Una cigüeña sobre un nido tejido de espigas y pámpanos, con esta letra: Pietas incomparabilis. Denotando la piedad y amor paternal con que Dios nos regala en este Sacramento" (figura 3).

La cigüeña sería imagen de Cristo que rodea a sus hijos del manjar de la salvación ${ }^{12}$. Pero apoyándonos que las fuentes literarias la idea específica es la Piedad de Dios como Padre, que da el alimento a sus hijos.

La cigüeña desde tiempos muy antiguos ha simbolizado la piedad, sobre todo filial, pues los hijos se ocupan de sus padres durante su vejez. Tervarent recoge cómo esa imagen se trasladó también al mundo religioso, como piedad cristiana ${ }^{13}$. Pero en este caso, lo que se quiere representar es el origen de ese comportamiento filial, pues como indica Alciato, no deja de ser una justa devolución de los favores: "Gratiam referendam" (emblema XXX).

Es interesante observar como va cambiando la pictura de este emblema en las diferentes ediciones del Emblematum Liber. En la edición princeps, de 1531, recogía esa referencia de la cigüeña hijo llevando sobre el lomo a su padre. Era uno de los primeros emblemas. En alguna de las ediciones de 1534, concretamente en la de París, pues no ocurre así en la de ese mismo año en Augsburgo, sigue esa imagen pero a la vez que lo lleva en el lomo, le da el alimento. Esa imagen se repetirá hasta 1556, como en la primera traducción al castellano de Bernardino Daza en Lyon en 1540 o incluso aquellas ediciones en las que se ha aumentado el número de emblemas, y la que nos ocupa se ha convertido en la número XXX. Pero en la edición lionesa de 1556, cambia la pictura, optándose por representar a los polluelos en el nido, y a la cigüeña padre trayéndoles la comida, que seguirá utilizándose con posterioridad. Ya no es tanto la piedad filial, sino la paterna, es decir el origen de ese comportamiento que deben tener los hijos hacia los padres.

En la custodia hispalense nos encontraríamos, por tanto, con esa imagen de la piadosa cigüeña, sobre el nido, pero no un nido cualquiera sino de pámpanos y espigas, destacando por su tamaño una de las espigas. Podría en realidad tratarse de la representación a través de la cigüeña de los fieles, alimentados por la espiga, símbolo eucarístico, que sería Cristo.

No encontramos la fuente exacta del mote. Pero sí podemos señalar como en 1598, en el túmulo que se levanta en las honras fúnebres en honor a Felipe II en la catedral de Sevilla ${ }^{14}$, aparece usado el mismo lema, acompañando a otro símbolo

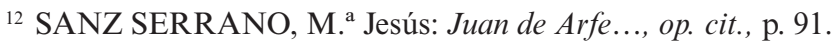

13 TERVARENT, Guy de: Atributos y símbolos..., op. cit., p. 158.

${ }^{14}$ COLLADO, Francisco Gerónimo: Descripción del túmulo y relación de las exequias que hizo la ciudad de Sevilla en la muerte del Rey Don Felipe Segundo, Sevilla, 1869, p. 187. PÉREZ ESCOLANO, Víctor: "Los túmulos de los reyes Felipe II y Margarita de Austria en la catedral de Sevilla", Archivo hispalense, Nº 185, 1977, pp. 149-178 
cristológico y eucarístico como es el pelícano. Muy probablemente el autor del programa iconográfico del catafalco fue el mismo canónigo Francisco Pacheco.

En el quinto encontramos "Una liebre que va a oler un racimo y unas espigas, $y$ la letra Vani sunt sensus hominis. Por la liebre se representan los sentidos, los cuales se engañan en la apariencia de pan y vino si no los esfuerza la Fe" (figura 4).

El lema está inspirado en el Libro de la Sabiduría 13, versículo 1: "vani sunt autem omnes homines quibus non subest scientia Dei".

Ya Sanz Serrano recogía como el simbolismo de la liebre desde la Edad Media estaba relacionado con lo impuro y concretamente con el pecado sexual ${ }^{15}$. Pero como se señala en el texto de Arfe lo que se busca aquí es simbolizar el engaño que producen los sentidos, y como es a través de la Fe en la Eucaristía, aludida tanto a través del racimo como de las espigas, como se debe practicar la misma.

En la custodia, por debajo de esta empresa aparece una cartela con la inscripción "RECTE ARCA / SACRAMENTORVM VIRGO/ MARIA FVIT S. Ild. Ser. 1 de Ass.". Es una cita tomada del sermón primero de la Asunción de María de San Ildefonso.

El sexto es "Una mano que tiene una vara, cuyo extremo se va convirtiendo en serpiente con esta letra: Hic vita, hic mors. Porque este Sacramento es juicio y condenación para aquellos que lo reciben indignamente, y vida para los que llegan a él con limpieza del alma. Alude este hieroglífico a la raza de Moisén, que fue salud para el pueblo de Israel, dándole paso por medio del mar, y haciéndola brotar fuente de aguas dulcísimas de la peña, y fue también horrible al pueblo Egipcio causando en él tan grandes plagas y estragos".

Arfe justifica el uso de la vara, aludiendo a dos pasajes del Éxodo, de la vida de Moisés a los que se recurre en muchas ocasiones en la iconografía hagiográfica, pero que en otras ocasiones adquieren un carácter alegórico, el paso por el medio del mar y el milagro de la Peña de Orbé (Éxodo 17). Según la Glosa ordinaria del benedictino Wilfrido Estrabon $(\uparrow 846)$, la fuente que hace brotar los golpes de Moisés no es sólo prefiguración del agua del Bautismo, sino el agua y la sangre del costado de Jesucristo en la cruz.

Es un episodio que aparece entre las escenas representadas en las tres custodias principales de Arfe, Ávila, Valladolid, y Sevilla. En este caso hace pareja con una escena claramente eucarística, que muestra el carácter tipológico que adquieren algunos de los episodios de la vida de Moisés en la custodia. Se trata de un relieve con la inscripción "Petra autem erat Christus" y que describe Arfe como "Al lado de esta está la figura de Cristo, de cuyo costado sale un arroyo de sangre, del cual beben algunas ovejas" 16 .

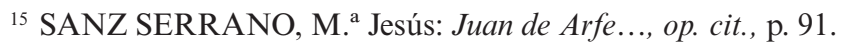

${ }^{16}$ Descripción..., op. cit., p. 10. SANZ SERRANO, M. . Jesús: Juan de Arfe..., op. cit., p. 86. 
El lema, basándonos en el sentido que quiere dar a la empresa Arfe, podría estar inspirado en textos muy habituales en contextos eucarísticos, como el Oficio del Corpus Christi de Santo Tomás de Aquino, o el himno Lauda Sion Salvatorem. La Eucaristía es a la vez vida para los que la practican de un modo puro, muerte para los impuros.

En el segundo cuerpo, los jeroglíficos se sitúan en el trozo de entablamento recto, que queda rehundido por encima de los arcos de ese cuerpo, en línea vertical con las del piso inferior.

El primer jeroglífico descrito por Arfe es "Un racimo atravesado en una vara $y$ rodeado de espigas, con esta letra: Caelestis patriae specimen. Significando, que como aquel gran racimo de uva, que trajeron Josué y Cales en sus hombros, fue muestra de la gran fertilidad de la tierra de promisión, así la grandeza y dulzor deste admirable Sacramento, que se nos da debajo de las especies de pan y vino, es más viva muestra y prenda de la hartura y abundancia del Reino de los bienaventurados" (figura 5).

Se trata de una referencia a un pasaje veterotestamentario de uso habitual en la iconografía eucarística: el regreso de Josué y los exploradores de la tierra de Canáan (Números 13). El sucesor de Moisés y su consejero, Josué, era efraimita y fue enviado junto con los representantes de las otras once tribus al país de Canaán, de donde volvieron cargados de frutos gigantescos destacando un racimo de uva del tamaño de un hombre. Este episodio permite relacionar la figura de Cristo y su sangre manando en la cruz con Josué, portador de ese gran racimo.

La idea que se quiere representar es que sólo a través de la práctica eucarística se llegará a la verdadera patria, el cielo, según nos indica el mote, del que no hemos localizado la fuente.

En la custodia de la Catedral de Valladolid ${ }^{17}$, aunque no tenemos total seguridad, puede estar representado el mismo tema, significando el consuelo que produce la práctica eucarística. Como en este caso sevillano, Arfe no recurre al tipo iconográfico más frecuente del episodio, dos hombres llevando un gran racimo colgando de una vara que sostienen sobre los hombros, si no que es una simplificación: en Valladolid un solo personaje con el racimo, en Sevilla el racimo únicamente.

A continuación, el segundo es "Una mano que extiende el índice, mostrando un cáliz con una hostia, y esta letra: Digitus Dei est hic. Dando a entender que el milagro deste Sanctísimo Sacramento es obra de la sabiduría eterna, que no la puede alcanzar la sabiduría humana" (figura 6).

"El dedo de Dios está ahí" es una expresión muy utilizada, con fuente en el capítulo 8 del Éxodo. Remite a las maravillas que es capaz de hacer Dios para mostrar su presencia. A los magos de Egipto no les quedó más remedio que reconocer

${ }^{17}$ ANDRÉS GONZÁLEZ, Patricia: Arte, fiesta e iconografía..., op. cit., pp. 102-103. 
la presencia de Dios en ese pasaje en el que Moisés convierte el polvo en una nube de mosquitos con sólo sacudir la tierra con su vara. Del mismo modo, se debe reconocer que en la Eucaristía está Dios. Por ello aparece ese dedo índice de la mano de Dios señalando un símbolo claro de la eucaristía, el cáliz con la Sagrada Forma.

Pero no sólo es reconocimiento de la obra de Dios, sino también de su eterna sabiduría, según explica Arfe. Y es que aquellos magos de Egipto eran además sabios, y tras esa muestra de fuerza, en la que van creando plagas (sangre, ranas...), al final tuvieron que reconocer la sabiduría eterna de Dios.

El tercer jeroglífico de este segundo cuerpo es "El arco del cielo, y sobre él el cáliz con una hostia, con esta letra: Signum foederis semptierni. Significando que así como dio Dios a Noé el arco del cielo en los siglos antiguos, por señal de alianza y amistad, así agora da su propia carne y sangre por más eficaz que verdadera prenda y señal de perpetua confederación con los hombres".

La fuente está en el pasaje del pacto entre Dios y Noé (Génesis, 9), como explica el propio Arfe. Lo que se busca es crear una similitud entre las "señales de pacto" de Dios como símbolos de su alianza: en el caso de Noé fue a través del Arco Iris, a los hombres a través de su carne y sangre.

En la literatura emblemática encontramos algunos emblemistas que han utilizado el arco iris con ese sentido de alianza. Así, el cartujo Dom Nicolás de la Iglesia lo emplea en su libro de emblemas dedicado a la Virgen de Miraflores ${ }^{18}$. Pero más relación con el de la custodia tiene el emblema 3, de la tercera centuria de Covarrubias Horozco, ya que utiliza la imagen del arco iris con el sentido de conciliación entre lo inferior y lo superior, "Concilians ima summis", indicando en el comentario: "El arco celeste que se causa de vapores que suben de la tierra, y se muestra a la puesta del sol, es figura de la Cruz de nuestro Redentor, cuyos braços forman un arco fuerte, cuyas saetas enclavaron a Satanás (...) Este mesmo arco, con sus braços, abraço cielo y tierra, y hizo paz entre dos tan distintos extremos, como Dios y el hombre" 19 .

${ }^{18}$ IGLESIA, Dom Nicolás de la: Flores de Miraflores, hieroglificos sagrados, verdades figuradas, sombras verdaderas del Mysterio de la Inmaculada Concepción de la Virgen y Madre de Dios María Señora nuestra, Burgos, por Diego de Nieva y Murillo, 1659, fol. 34v. Vid. ANDRÉS GONZÁLEZ, Patricia: "Emblemas marianos en la capilla de la Virgen en la Cartuja de Burgos: el modelo pintado y su repercusión iconográfica", Boletín del Seminario de Estudios de Artes y Arqueología, 69-70, (2003-2004), pp. 383-409. ESCALERA PÉREZ, Reyes: "Jeroglíficos de la Inmaculada Concepción. Flores de Miraflores de fray Nicolás de la Iglesia (1659)", en ARANDA DONCEL, Juan (Coord.): Las advocaciones marianas de Gloria. Actas del I Congreso Nacional, Córdoba, 2003, pp. 165-178. ID.: "Emblemática mariana. Flores de Miraflores de Fray Nicolás de la Iglesia", Imago. Revista de cultura visual, n.1, 2009, pp. 45-63.

${ }^{19}$ COVARRUBIAS HOROZCO, Sebastián. De: Emblemas Morales, Madrid, 1610 (ed. facsímil e introducción de Bravo Villasante, C. Madrid, F.U.E., 1978), emb. 3, III 
En el cuarto se han representado "Dos rayos cruzados, en medio un ramo de oliva con esta letra: Recordabor foederis mei vobiscum. Que son palabras que dijo Dios a Noé cuando hizo con él la dicha alianza y por esto se da a entender la clemencia con que trata Dios al género humano en la institución de este Sanctísimo Sacramento, olvidando sus ofensas, y celebrando con él perpetua paz y amistad" (figura 7).

Sigue este jeroglífico con la referencia a Noé, tanto en el lema como en la empresa. Los rayos podrían ser una forma de aludir al Diluvio, aunque aquí también tienen otro sentido, y la rama de olivo referencia al momento en que cesa. Pero además, el motto está tomado del siguiente capítulo del Génesis, al que ya se aludía en la empresa anterior con el arco iris.

Como es sabido, el ramo de olivo simboliza esa paz y amistad de la que habla Arfe en su Descripción, que son muestra de la clemencia de Dios quien llega a olvidar las ofensas, representadas a través de los rayos cruzados según nos indica.

En el segundo cuerpo de la misma custodia hispalense, entre las alegorías de los dones que proporciona el sacramento de la Eucaristía, figura una representación en la que el ramo de olivo alude también a la idea de reconciliación. Dice Arfe: "5. Paz y aplacacion de la ira de Dios, la cual tiene un ramo de oliva, y en la otra mano el cuerno de la copia lleno de uvas y espigas, y la letra: Reconciliatio".

El siguiente jeroglífico, el quinto, es "El pelícano cómo da vida con la sangre de su pecho a sus hijos, con esta letra: Majorem charitatem nemo habet”.

El lema se inspira en San Juan 15, 13, en un pasaje de fácil interpretación eucarística, ya que Jesús es presentado como la vid (No hay mayor acto de amor o caridad que dar la vida por el otro, como hace Jesús).

También el pelícano es un símbolo muy frecuente en las representaciones de carácter eucarístico, derivado del relato en el que el pelícano se picotea el pecho para dar de comer a sus polluelos. La asimilación a la figura de Cristo empezó en época medieval, fundamentalmente difundido por los Bestiarios ${ }^{20}$, adaptándose al simbolismo eucarístico, ya que recuerda el momento en que el costado de Cristo es abierto, y mana la sangre luego convertida en vino ${ }^{21}$. Recordemos la conocida expresión de Santo Tomás de Aquino en el sexto cuarteto del himno "Adoro te Devote": "Pie pelicane, Jesu Domine / Me immundum munda tuo sanguine / Cujus una stilla salvum facere / Totum, quid ab ovni mundum scelere”.

cent., fols. 203-203v.

${ }^{20}$ ANDRÉS ORDAX, Salvador: Iconografía cristológica a fines de la Edad Media: El crucero de Sasamón, Salamanca, 1986, pp. 70-73. GARCÍA ARRANZ, José Julio: Ornitología emblemática..., op. cit., pp. 627-656. SÁNCHEZ LÓPEZ, Juan Antonio, "Iconografía e iconología del pelícano: un ensayo sobre la reconversión del concepto de Filantropía", Boletín de Arte, 1991, n 12, pp. 127-146.

${ }^{21}$ ANDRÉS ORDAX, Salvador: "La Eucaristía en el arte", Corpus, historia de una Presencia, Toledo, 2003, pp. 35-51. 
Son muchas las obras de arte, en las que aparece el pelícano golpeándose el pecho, como sagrarios y piezas eucarísticas, pero también rematando un Crucificado como en el retablo mayor, obra de Gil de Siloé, de la iglesia de la Cartuja de Miraflores (Burgos) o en el árbol de San Buenaventura. En la literatura emblemática también figura con simbolismos como la caridad o la bondad. Y por supuesto para remitir a la Pasión de Cristo, por ejemplo en los Emblemas Chrestienes et Morales de Zacharias Heyns, en De l'art des devises de Pierre le Moyne, tal y como recoge García Arranz ${ }^{22}$.

Destacamos uno de los señalados por este autor, el emblema XX del tercer libro de $A$ collection of emblemes de George Wither, basados en los de Gabriel Rollenhagen ${ }^{23}$. En él nos encontramos en un primer plano al pelícano alimentando a sus polluelos con su propia sangre, mientras al fondo figura Cristo en la cruz rodeado de fieles que recogen su sangre en cálices.

En la custodia de la catedral de Valladolid ${ }^{24}$, una de las empresas recoge la imagen del pelícano, acompañado del lema "Sic fit digna domus", en el que se muestra la Pasión de Cristo, y muy concretamente la crucifixión, como el momento en que Cristo construye una digna casa, para aquellos que practican la Eucaristía. En Sevilla, nos enseña cómo es el mayor acto de caridad, dar la vida por sus hijos.

El sexto es "Un león muerto de cuya boca sale un enjambre de abejas, con esta letra: De forti dulcedo. Dando a entender que como de aquella fiera tan brava salió cosa tan dulce como la miel, así del brazo León del tribu de Judá, Dios de venganzas, había venido a tanta llaneza y amor con el hombre, que se ofrecía por su propio manjar".

El lema, "De los fuertes, la dulzura", y la pictura están tomados del libro de los Jueces, 14, 14 "Et de forte egressa es dulcedo". El enigma se basa en el pasaje de Sansón a cuando se encuentra con un león al que da muerte. Un tiempo después, lo vuelve a encontrar y en su boca había un enjambre de abejas y un panal de miel.

En la literatura emblemática lo han utilizado, entre otros, Saavedra Fajardo en sus Empresas políticas, en concreto la empresa XCIX, "Merces belli"25. Aquí adquiere un carácter político, relacionando el fin de la guerra con la paz y la benignidad. Es una idea semejante a la que presentaba Alciato en su emblema CLXXVII, con un yelmo del que salían las abejas.

Sin embargo, el jeroglífico de la custodia arfiana no tiene una elaboración tan complicada, sino que remite a cómo Dios puede ser a la vez fuerte y dulce.

${ }^{22}$ GARCÍA ARRANZ, José Julio: Ornitología emblemática..., op. cit., pp. 642-644.

${ }^{23}$ WITHER, George: A Collection of Emblemes, Londres, 1635.

${ }^{24}$ ANDRÉS GONZÁLEZ, Patricia: Arte, fiesta e iconografía..., op. cit., pp. 119-120.

${ }^{25}$ GONZÁLEZ DE ZÁRATE, Jesús María: Saavedra Fajardo y la literatura emblemática, Valencia, 1985, pp.110-112. 
El tercer cuerpo tiene seis empresas: "Entre los arcos de este cuerpo están los seis hieroglificos siguientes y la letra de ellos encima en una cartela". Efectivamente, como dice Arfe, la colocación de las mías varía respecto a los dos cuerpos inferiores. Las empresas no están en la misma vertical, sino que se encuentran en los intercolumnios. Además, los motes se encuentran situados por encima de las picturas de las empresas, en unas cartelas independientes. Están escritas en mayúsculas. Son por tanto, muy diferentes a los de los dos cuerpos inferiores, en los que los lemas aparecen por debajo y en letra cursiva.

En este cuerpo nos encontramos con diferencias entre el texto de la Descripción y las empresas que han llegado hoy en la custodia, fundamentalmente porque no coinciden los motes descritos con los que aparecen hoy en día.

La primera empresa que describe Arfe es "Un fénix, que se enciende y tiene esta letra: Instauratio generis humani". Sin embargo, en la custodia nos encontramos que a la pictura donde aparece el Fénix, el mote es diferente, pues pone "AETERNVM SA/CRIFICIVM", que es la que aparece en la fuente literaria con la sexta empresa.

En la pictura sí que aparece la imagen del Ave Fénix en el nido ardiendo. Como es conocido, éste es otro de los animales más empleados en la iconografía cristológica, con muchos significados, pero sobre todo como alegoría de la resurrección. Recordemos la famosa descripción simbólica de Tomás de Cantimpré, en el Codex Granatensis: "Simboliza las almas santas que llevan una vida sencilla hacia la Santa Trinidad y firmemente apoyada sobre las cuatro virtudes cardinales: prudencia, templanza, justicia y fortaleza. En su tamaño como el águila, simboliza la elevación de la santa contemplación; con su hermosa cabeza, simboliza la pureza de pensamientos. Su pico empenachado simboliza el doble gozo de la oración: el de la seguridad propia y ajena. Su cuello áureo, la esperanza serena que procede de la caridad. El color de púrpura en la parte posterior, simboliza la aceptación de la pasión de Cristo mediante la mortificación de la carne"26.

Ruscelli en la empresa que dedica al Conde de la Trinidad, Giorgio Costa, utiliza la imagen del Ave Fénix que se renueva en el fuego, como imagen el ánimo invicto reforzado por la gracia divina, que serían los rayos del sol ${ }^{27}$. Pero en el caso de la custodia hispalense, el sentido sería el más habitual, la resurrección.

Su mote original, según la descripción de Arfe sería Instauratio generis humanis. Así, se aludiría a cómo Cristo con su resurrección instaura al género humano, al tiempo que lo alimenta con su cuerpo y sangre a través de la eucaristía.

En cambio, el mote que figura hoy en la custodia, "Aeternum sacrificium" podemos relacionarlo con el capítulo 10 de los Hebreos, concretamente el versículo 14: "una enim oblatione consummavit in sempiternum sanctificatos", donde se

${ }^{26}$ CANTIMPRÉ, Tomás de: Codex Granatensis, 1400, p. 203.

${ }^{27}$ RUSCELLI, Girolamo: Le impresse illustri..., Venecia, 1588, pp. 220-225. Vid. GARCÍA ARRANZ, José Julio: Ornitología..., op. cit., pp. 349-350. 
reconoce el valor del sacrificio de Cristo. Esta hipótesis la basamos en la posible similitud con el programa de las empresas de la custodia vallisoletana, como veremos en la última empresa de este cuerpo. En este caso, el cambio de lema concuerda con la significación del Ave Fénix como eterno sacrificio del padre por los hijos.

La segunda empresa de este tercer cuerpo es una interpretación de una imagen muy famosa en la literatura emblemática. "Dos cornucopias que cruzan y una cruz en medio; los cornucopias están llenos de pámpanos y espigas, con esta letra: Felicitas humani generis" (figura 8).

La cornucopia, símbolo de la abundancia, en esta ocasión llena de atributos eucarísticos como los pámpanos y las espigas, representarían el bienestar, la felicidad de los hombres. Este sentido aparece explicado en la alegoría de la "Felicidad. En la Medalla de Julia Mamea", de Cesare Ripa, que lleva la siguiente inscripción: "Foelicitas Publica" 28 . Y explica como la cornucopia alude a "el fruto que con las fatigas y trabajos se consigue, sin las cuales es claramente imposible alcanzar la Felicidad, que sólo con el esfuerzo se conoce y desea". Pero también puede simbolizar "las riquezas, pues llamamos felices a aquellos que entre nosotros poseen tanta abundancia de bienes temporales que siempre pueden proveer a las necesidades del cuerpo, siendo además tan virtuosos que también logran subvenir a las que el alma siente".

Pero aquí están centradas por una cruz, siendo claramente una versión del famoso emblema de Alciato, "FORTUNA COMES VIRTUS" (emblema CXVIII). No es la concordia, la paz representada a través del caduceo, la que produce la abundancia como en aquel, si no Cristo con su sacrificio en la cruz, con su muerte y posterior resurrección, el que da el alimento y con ello la felicidad.

Como en el caso anterior, el lema que cita Arfe en la Descripción no es el que aparece en la custodia tal y como se encuentra hoy en día. En ella, pone "INSTAVRACIO GENERIS HVMANIS", que corresponde en realidad con la primera empresa de este cuerpo. Desconocemos en qué fuente se podría basar, y tampoco tendría mucho sentido en relación con esta pictura.

Lógicamente, la que cita Arfe en su descripción sí que tiene más sentido, la felicidad, representada por la cornucopia, viene dada a los hombres por el sacrificio de Cristo.

La tercera empresa es "Una ave Alción, que está sobre sus pollos en un nido de pámpanos y espigas con esta letra. Tranquilitas immutabilis. Significando el estado sosegado y quieto de los bienaventurados, que se da a entender por el nido del Alción, que cuando anda sobre la mar, calman y cesan todas las tempestades".

La pictura descrita por Arfe de esta empresa recoge la imagen más frecuente en las representaciones literarias y artísticas de este ave conocido también como

${ }^{28}$ RIPA, Cesare: Iconología, Madrid, 2007, tomo I, p. 411-412. 
Martín Pescador. Responde a la idea, que viene de la Antigüedad y ya recogiesen autores como Aristóteles, de que este ave, que pone los huevos en torno al solsticio de invierno, sólo hace su nido cuando sabe que los polluelos saldrán adelante y no habrá durante al menos siete días circunstancias meteorológicas adversas, por lo que se consideraba que predecía la bonanza en la costa. Muchos autores clásicos lo recogen y posteriormente teólogos y padres de la Iglesia o los bestiarios lo adaptan al mensaje cristiano.

Esta abundancia de referencias justifica que sea un ave muy utilizado en la literatura emblemática, partiendo del mismo Alciato que lo emplea ya en la edición princeps de 1531 (emblema "Ex pace ubertas") para simbolizar la bonanza en tiempos de paz. Juan de Borja utilizará esta imagen, pero colocando el nido en el medio del mar calmado, con el mote "Tranquilitas foecunda"29.

Con sentido eucarístico lo emplea Chesnau en su emblema XXVIII, "Ex latebris coelumque solumque serenat" ${ }^{30}$. En él, y como ya apareciese en algunos autores medievales, el Alción es Cristo que libera al hombre de todas las tempestades producidas por el pecado, gracias a su muerte en la Cruz.

Ya unos años antes, 1611, Gabriel Rollenhagen lo utiliza en un sentido similar, pero colocando el nido en medio de una mar lleno de olas, mostrando como la protección de Dios, daría tranquilidad, "Mediis tranquillus in undis"31.

Según explica Arfe, ese sería el sentido que se quiere dar aquí: los polluelos serían los bienaventurados que participan de la eucaristía, y reciben una tranquilidad eterna gracias al Padre, Jesús, convertido en Alción, que les da su casa, a través de la eucaristía.

La cuarta es "Un carro con llamas de fuego, que sube al cielo con esta letra: Sic itur ad astra. Por lo cual se da a entender, cómo este Sanctísimo Sacramento es viático de los que caminan al cielo, porque Elías fue de esta manera arrebatado después que Dios le envió el pan con el ángel y con el cuervo" (figura 9).

El lema es una máxima de Virgilio, "así se va a las estrellas" en el libro IX de la Eneida, cristianizada con la clara referencia a Elías en la pictura. Pero una vez más nos encontramos con que en la realización de la custodia se han cambiado los motes y en la actualidad figura el mote de la quinta empresa, "Delitiae generis humani".

En la custodia de la catedral de Valladolid ${ }^{32}$, en una de las escenas veterotestamentarias representadas en el plinto del primer cuerpo, figura también este pasaje de Elías (IV Reyes 2), adaptado al sentido eucarístico, gracias a la inscripción que lo acompaña: "PIGNVs GLORIAE”. Allí se representaba como Elías llevado hacia el cielo muestra el camino a los fieles, participando de la eucaristía. Aquí, en la

\footnotetext{
${ }^{29}$ GARCÍA MAHÍQUES, Rafael: Empresas morales de Juan de Borja, Valencia, 1998.

${ }^{30}$ CHESNAU, Augustin: Orpheus... op. cit.

${ }^{31}$ ROLLENHAGEN, Gabriel: Nucleus emblematum selectissimorum, Arnheim, 1611.

${ }^{32}$ ANDRÉS GONZÁLEZ, Patricia: Arte, fiesta e iconografía..., op. cit., pp. 91-92.
} 
custodia de Sevilla representaría cómo la práctica eucarística muestra el camino al cielo, a las estrellas.

La quinta empresa son "Dos delfines que cruzan por las colas, y tienen en medio un cáliz con su hostia, con esta letra: Delitiae generis humani. Por el cual hieroglifico se significa el deleite y amor con que Dios regala a los hombres con este Sacramento" (figura 10).

El delfín es símbolo de la ligereza, pero también atributo del amor, si seguimos los Fastos de Ovidio (v. 81) "fuit occultis felix in amoribus index". Alciato los utiliza, también cruzando la cola, en el emblema CLVI, "In mortem praeproperam", indicando cómo el amor pasa con rapidez y lo que queda después es tan solo el sepulcro, coronado por la cabeza de la Gorgona Medusa.

En la custodia de Sevilla, los dos delfines muestran ese amor que regala Dios, pero que lo que realmente quedará es la práctica de la Eucaristía, representada por el cáliz y la sagrada forma. Esto será lo que dará las delicias al ser humano, como indica el lema, que podría estar inspirado en el Libro de los Proverbios, 8, 31, en cuyo texto se advierte a los hombres que deben seguir a Dios: "Día tras día me llenaba yo de alegría, siempre disfrutaba de estar en su presencia; me regocijaba en el mundo que él creó; jen el género humano me deleitaba! Y ahora, hijos míos, escúchenme: dichosos los que van por mis caminos. Atiendan a mi instrucción, y sean sabios; no la descuiden. Dichosos los que me escuchan y a mis puertas están atentos cada día, esperando a la entrada de mi casa. En verdad, quien me encuentra, halla la vida y recibe el favor del Señor. Quien me rechaza, se perjudica a sí mismo; quien me aborrece, ama la muerte".

$\mathrm{Su}$ lema ha cambiado, figurando en la actualidad el de la empresa cuarta, sin tener entonces sentido entre mote y pictura.

La sexta y última empresa es "Un altar adornado con sus festones de pámpanos y espigas, y en él están unas llamas de fuego, con esta letra: Aeternum sacrificium”.

Siguiendo con el hilo conductor de las empresas de este tercer cuerpo, se alude al sacrificio de Jesús con su muerte, a través de una referencia muy clara a la eucaristía, un altar decorado con pámpanos y espigas.

Aventurando una posible fuente, creemos que podría tratarse de una referencia o alusión al sacrificio de Elías en el monte Oreb, que también aparece en el programa iconográfico de la catedral de Valladolid. Se trata de un tema que normalmente es utilizado por los teólogos y escritores como símbolo del Espíritu Santo, pero que también puede ser leído bajo una visión eucarística. Según aparece narrado en el libro I Reyes, 18, 20-40, Elías desafía a los ochocientos cincuenta profetas del dios Baal a hacer un sacrificio a sus dioses, levantándose dos altares. Uno de ellos no tiene ningún efecto, a pesar de los esfuerzos de los sacerdotes de Baal, mientras que el de Elías se consume enseguida, por un fuego que viene desde el cielo.

Y siguiendo con esa hipótesis de una posible similitud con las empresas de Valladolid, creemos que la fuente del lema podría ser el capitulo 10 de los Hebreos, 
concretamente el versículo 14 ("Una enim oblatione consummavit in sempiternum sanctificatos”), donde se reconoce el valor del sacrificio de Cristo.

Sin embargo, en la actualidad la custodia presenta el mote cambiado, figurando en la misma el que Arfe adjudica a la segunda empresa, "FELICITAS HVMANI GENERIS".

\section{CONCLUSIONES}

Tras el análisis individual de los jeroglíficos y empresas, podemos extraer algunas particularidades significativas, que destacamos a modo de conclusión.

En primer lugar, llama la atención que la colocación de las empresas en los tres cuerpos no es la misma, pues se van a adaptando al perfil de cada uno de los entablamentos que ocupan. Así, en el primer cuerpo, se colocan en el medio de cada tramo curvo y sobresaliente de la planta; en línea con ellas, las empresas del segundo cuerpo se sitúan en el trozo de entablamento recto, que queda rehundido por encima de los arcos de ese cuerpo; pero en el tercero, las empresas no están en la misma vertical, sino que se encuentran en los intercolumnios. En el caso de la custodia de Valladolid esto no ocurre, figurando las empresas en la misma vertical.

Además, hay una importante diferencia entre las formas emblemáticas utilizadas: en los dos primeros cuerpos los lemas de las empresas, escritos en minúsculas, se sitúan por debajo del cuerpo de las mismas, casi como una mera inscripción aclaratoria. Se asemeja a las diferentes leyendas de las abundantes escenas vetero y neotestamentarias de los plintos de cada cuerpo. En cambio, las del tercer cuerpo presentan una cartela superior donde figura el motto, en mayúsculas y por debajo en otra cartela el cuerpo. Esta diferencia, hace que podamos considerar las formas utilizadas en los dos primeros cuerpos más como unos jeroglíficos, mientras que las del superior recuerdan la forma de una empresa.

Este detalle resulta significativo si lo comparamos con la siguiente custodia realizada por Arfe, la de la catedral de Valladolid, en la que las formas utilizadas son todas ellas empresas, perfectamente construidas y con una elaboración intelectual magnífica, que tiene que deberse a algún canónigo de la catedral, por ahora desconocido. En su primera gran custodia procesional, la de Ávila, no aparecían todavía formas emblemáticas. Seguramente el ambiente humanístico de Sevilla en el que Arfe se movió y el contacto directo en concreto con el canónigo Francisco de Pacheco, creador del programa iconográfico de la custodia hispalense, le permitiría conocer este tipo de lenguaje muy conocido a finales del siglo XVI. A pesar de ello, las que utiliza en Sevilla no resultan de la complejidad intelectual ni del conocimiento de la literatura emblemática que encontramos en Valladolid. Lo que nos lleva a destacar cómo, entre la realización de una obra y otra, se ha comprendido lo que es una empresa y las utiliza perfectamente en la segunda. 
Finalmente, el programa iconográfico esté magníficamente diseñado, insertándose las empresas y jeroglíficos con el conjunto a la perfección. Los tipos iconográficos utilizados son muy habituales en contextos eucarísticos, como el cáliz y la sagrada forma que aparecen en varias ocasiones, o de mayor simbolismo como son el pelícano, el racimo en la vara, pámpanos, espigas...

La lectura del conjunto es compleja, y se podría hacer en un doble sentido. Por un lado nos encontramos la correspondencia con la explicación que da Arfe en la Descripción sobre el conjunto. El primer cuerpo estaría dedicado a la Fe luchando con la Herejía (recordemos que esta parte ha perdido el sentido al haber sido modificada en el siglo XVII) y el segundo al Sacramento propiamente dicho. En las empresas de estos dos cuerpos nos encontramos como se reiteran ideas semejantes en torno a la eucaristía, los beneficios que aporta la práctica eucarística, si bien en el inferior se expresa a través de la contraposición de conceptos, queriendo indicar como puede llegar a todos, simbolizando la unión (granada), los infieles (polluelos de cuervo), la escasez (ausente en las sietes espigas)... Mientras que en el segundo cuerpo es ya la plenitud de dichas ideas, el gozo o disfrute del sacramento. Así aparecen la unión (arco iris), el alimento espiritual (león muerto con el enjambre de abejas de la boca), la abundancia (racimo en la vara), la piedad o el amor (pelícano), la fe (dedo que señala el cáliz), y la vida eterna (rayos cruzados con el ramo de olivo).

El tercer cuerpo dice Arfe que se dedica a la Historia del Cordero y las empresas representadas giran todas ellas en torno entorno a un simbolismo cristológico, refuerzan la idea del sacrificio de Cristo en la cruz: fénix que resucita, la cruz en medio de las cornucopias, el ave Alción, el camino al cielo en el carro, los delfines o el último, el altar decorado como pámpanos y espigas.

Pero además, se puede ver otra posible agrupación temática de las empresas: las que ocupan el primer cuerpo giran en torno al pan, la carne; las del segundo, sobre la sangre, el vino; mientras que las del tercero aluden directamente a Cristo.

Fecha de recepción: 26 de septiembre de 2014

Fecha de aceptación: 28 de noviembre de 2014 


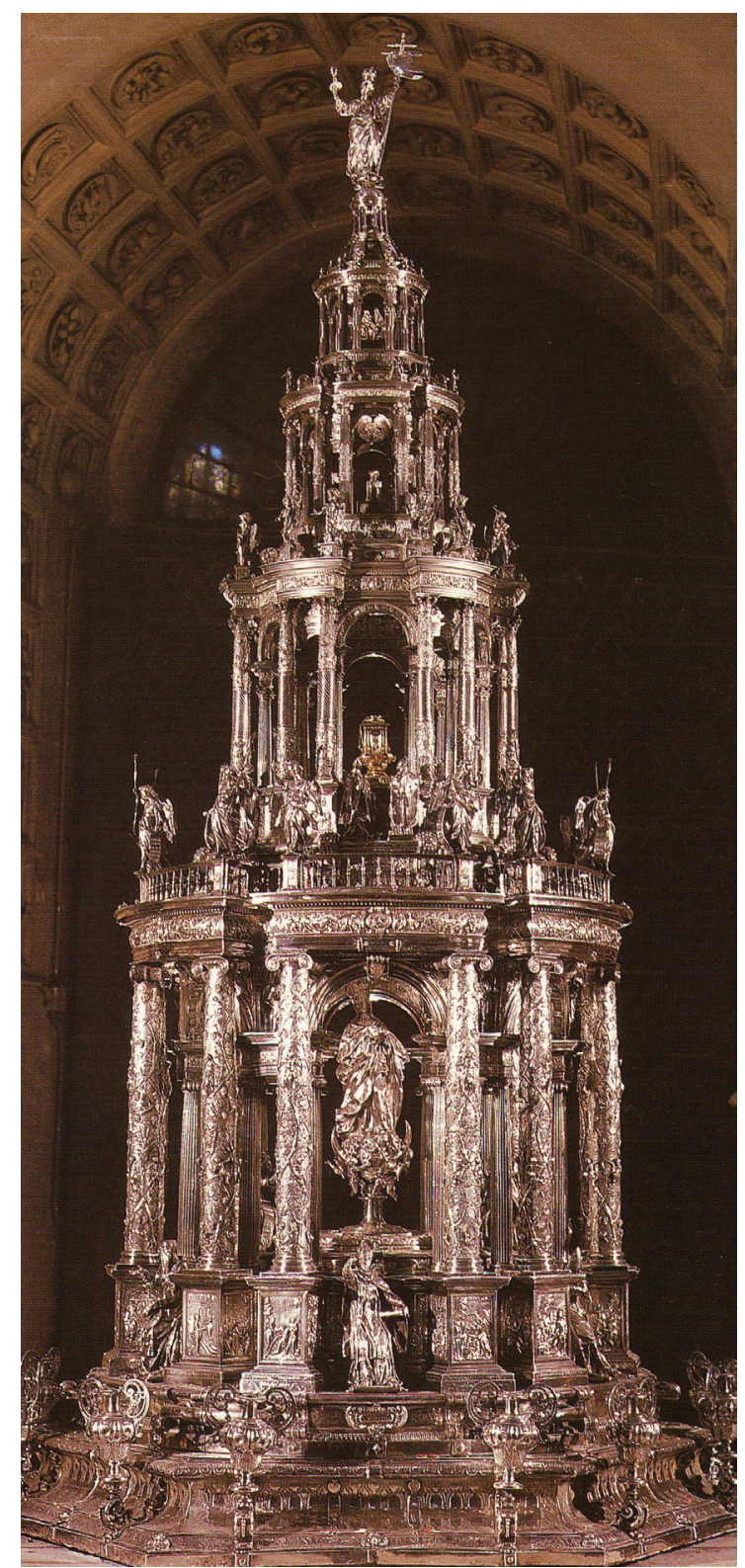

Figura 1. Custodia procesional de la catedral de Sevilla. Juan de Arfe. 1580-1587. 

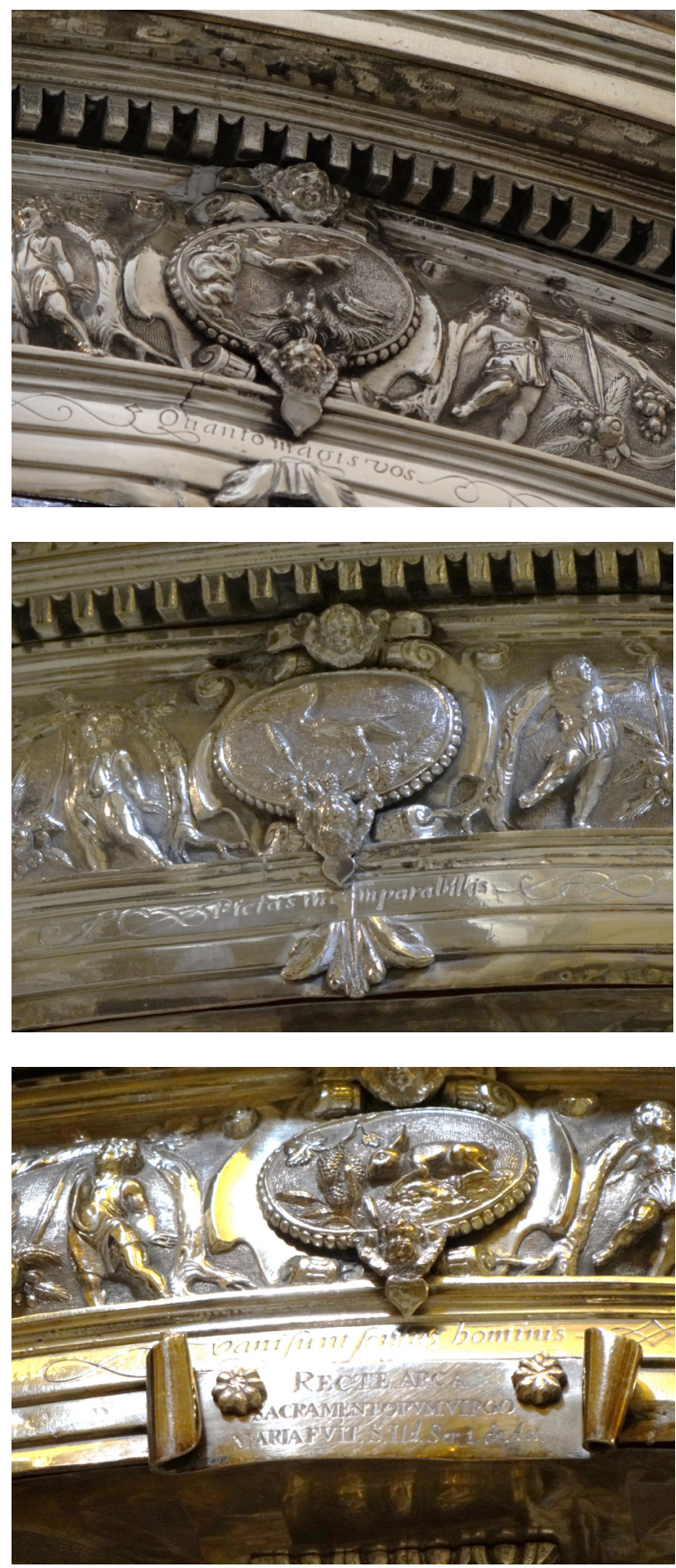

Figura 2. Jeroglífico segundo del primer cuerpo: "Quanto magis vos".

Figura 3. Jeroglífico cuarto del primer cuerpo: "Pietas incomparabilis".

Figura 4. Jeroglífico quinto del primer cuerpo: "Vani sunt sensus hominis". 
Figura 5. Jeroglífico primero del segundo cuerpo: "Caelestis patriae specimen".

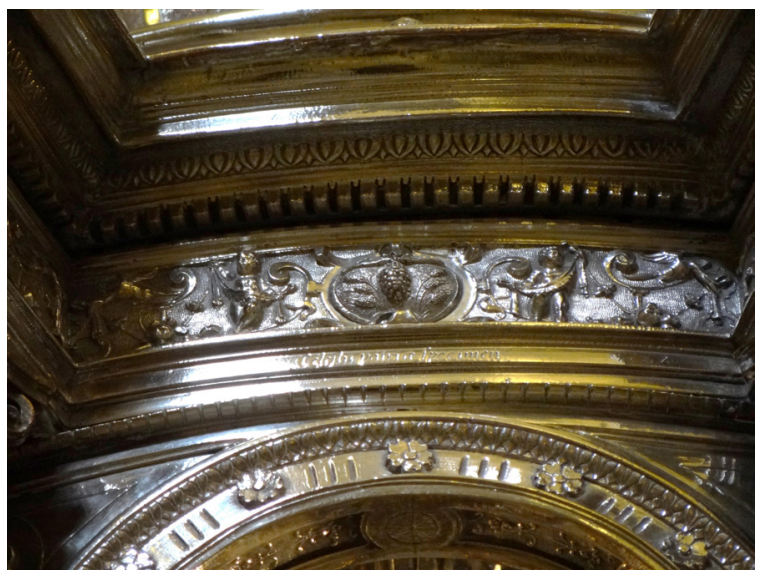

Figura 6. Jeroglífico segundo del segundo cuerpo: "Digitus Dei est hic".

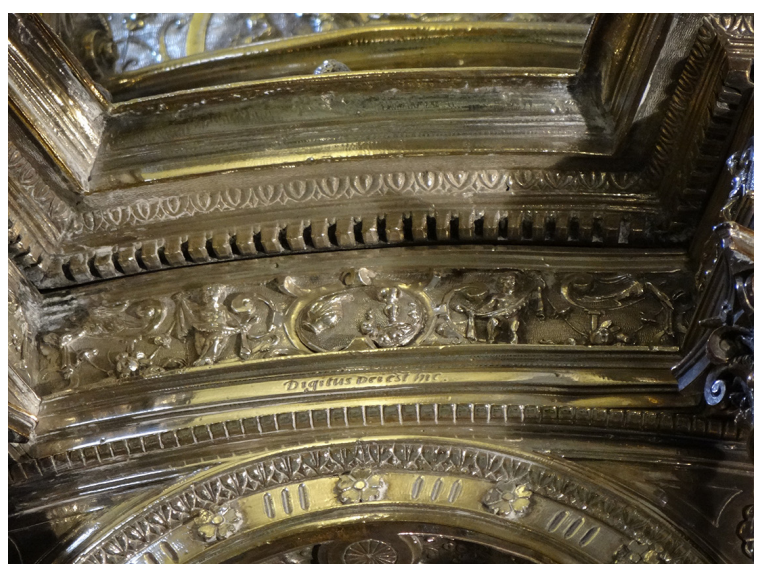

Figura 7. Jeroglífico cuarto del segundo cuerpo: "Recordabor foederis mei vobiscum".

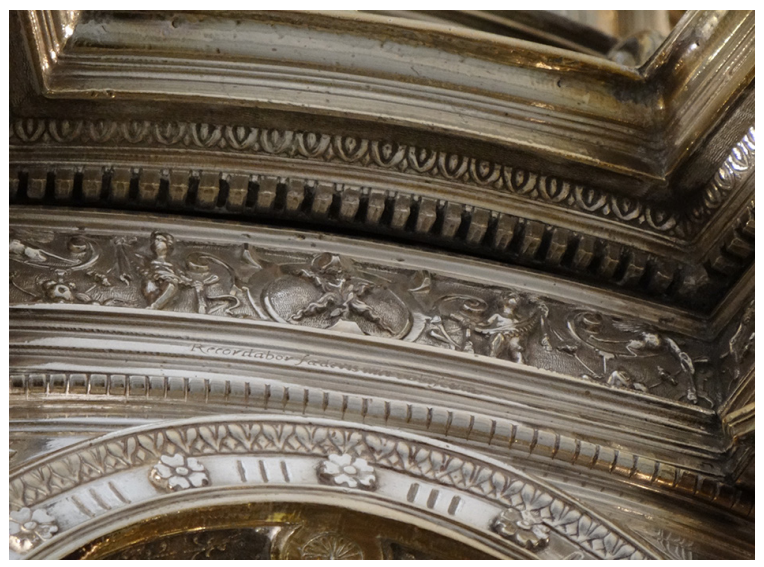



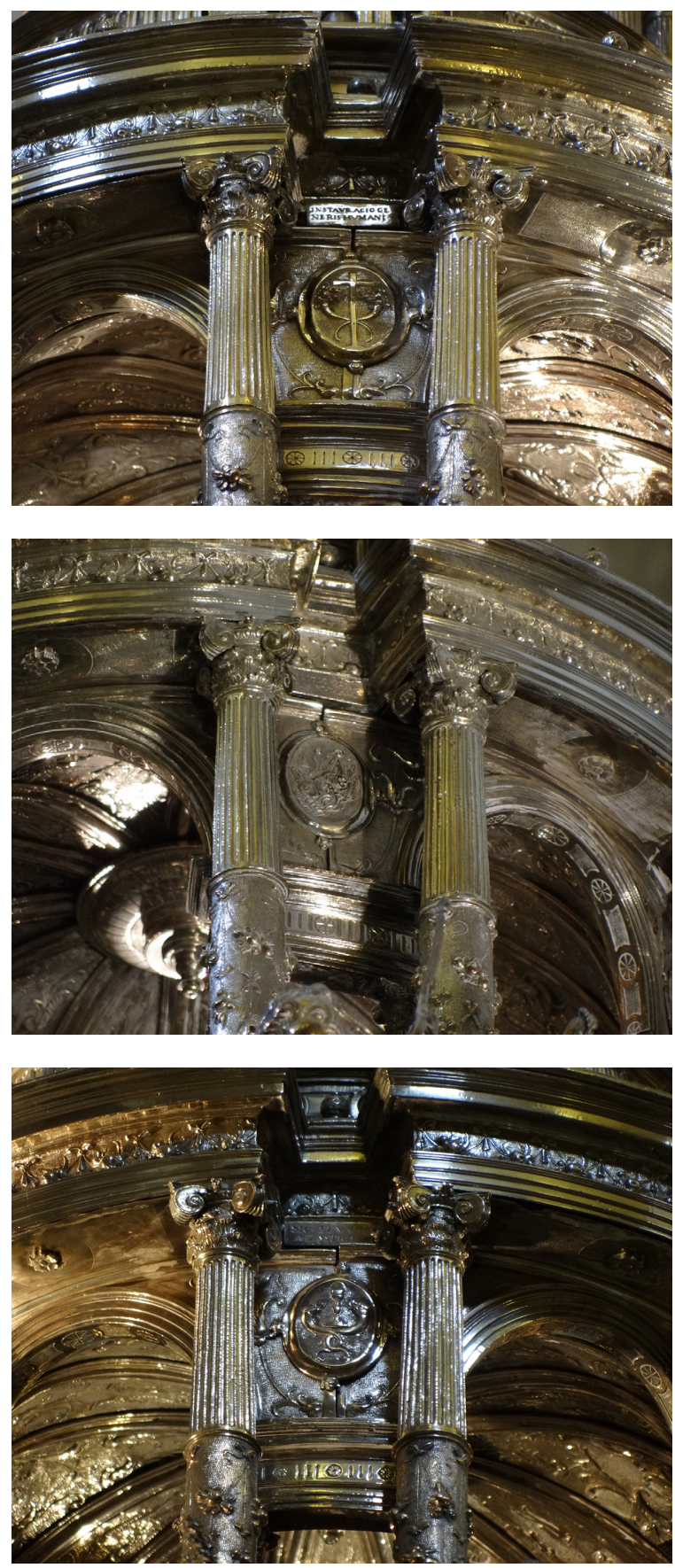

Figura 8. Empresa segunda del tercer cuerpo: "Felicitas humani generis".
Figura 9. Empresa cuarta del tercer cuerpo: "Sic itur ad astra”.
Figura 10. Empresa quinta del tercer cuerpo: "Delitiae generis humani". 